Effects of Two

\section{Contrasting School}

Task and Incentive

Structures on

Children's Social

Development

\author{
Jacques S. Benninga \\ Susan M. Tracz
}

California State University, Fresno

Richard K. Sparks, Jr. Valley Oak Elementary School, Clovis, CA

\section{Daniel Solomon \\ Victor Battistich}

Developmental Studies Center, San Ramon, CA

\section{Kevin L. Delucchi}

San Francisco State University

\section{Ronald Sandoval}

De Paul University

\section{Beverly Stanley \\ University of Washington}

The Elementary School journal

Volume 92, Number 2

(C) 1991 by The University of Chicago. All rights reserved. 0013-5984/92/9202-0002\$01.00

\begin{abstract}
Students (second through fifth graders) in 2 elementary school programs with very different structures in 2 districts were compared over 4 years on measures of social development. One program (EXS) emphasized an external motivational orientation with a focus on student accountability and a management system based on competition. The other (CDP program) focused on helping children develop an internal commitment to values and norms through a focus on developmental discipline, cooperative learning, helping activities, social understanding activities, and prosocial values. The 1 EXS school, 3 CDP program schools, and a group of 3 CDP comparison schools that were not implementing any specific intervention program, shared generally similar demographic characteristics. Over the 4 years students were assessed on a number of instruments including structured classroom observations, individual student interviews, large-group questionnaires, and small-group tasks (4-person and dyadic). In addition, teachers completed an extensive questionnaire related to program philosophy and implementation. Results showed the schools to be different in ways consistent with their intended philosophies, with the EXS classrooms using more external controls and the CDP classrooms using more prosocial activities. The EXS teachers described their school as more active, businesslike, traditional, creative, innovative, and supportive. Students in the EXS school demonstrated higher self-esteem than did the CDP students over a 2-year period. Motivation for prosocial behavior was more extrinsic in the EXS school and more intrinsic in the CDP program schools. Third-grade students' interpersonal behavior was more helpful and supportive in the CDP schools.
\end{abstract}

Substantial knowledge has accumulated over the past few decades concerning the effects of school instructional approaches on students' academic achievement. Much less attention has been devoted to investi- 
gating the school determinants of students' social development, and, hence, much less is known in this domain. Increasing knowledge about the effects of school instructional systems on students' social development could help educators create school environments that enhance both social and academic progress.

Two important components of instructional systems in schools are the instructional task structure and the student incentive structure (Slavin, 1983). Task structure refers to the ways the teacher organizes learning activities for students (e.g., grouping patterns such as cooperative, competitive, or individualistic); incentive structure refers to sources of students' motivation to perform (generally categorized into extrinsic incentives, such as rewards or grades, and intrinsic incentives, such as inherent task interest or perceived relevance to personal goals). To some degree, these components are independent. Cooperative activities can be motivated by either extrinsic or intrinsic incentives and sometimes by combinations of the two. The same is true of individualistic learning activities. Competitive task structures usually are thought of as those that require individuals or groups to demonstrate superiority to the performance or product of another individual or group; this constitutes an extrinsic incentive structure.

Although the benefits of cooperative learning have been prominent in recent literature describing school task structure, there is still controversy concerning the relative advantages and disadvantages of cooperative versus competitive modes of organizing classroom activities. Numerous studies have shown students in cooperative learning structures to exceed those in competitive or individualistic learning structures in terms of achievement, self-esteem, positive interpersonal behavior, positive intergroup behavior, and other variables (see Johnson, Johnson, \& Anderson, 1983; Johnson, Johnson, \& Maruyama, 1981; Sharan, 1980; Slavin, 1983,1984,1987). These studies reported that students working in co- operative groups were more likely to perceive themselves doing "a good job" and feeling better about it than were students in either competitive or individualistic learning environments. Students working in cooperative groups provided each other with greater peer support and evidenced higher levels of affective perspective taking. Johnson and Johnson (1974) suggested that "one probable and undesirable affective outcome of a pervasive competitive situation is that individuals will try to obstruct each other's goal accomplishment. They will have hostile and angry feelings toward individuals who win and thus relegate them to failure, or they will become angry at the teacher, at the school, or at themselves" (p. 225).

In contrast, Michaels (1977) reviewed evidence indicating that "individual competition was the most effective reward structure implemented in strengthening the independent task (i.e., academic) performance of students" (p. 95). In addition, Barnett, Matthews, and Howard (1979) dispute the negative association between competitive experiences and the development of empathic capacities in children.

Slavin (1984) concluded from a review of numerous studies that, although group learning is important to academic achievement, group rewards (combined with individual accountability) may be the essential element, functioning to promote and maintain student academic motivation. As Slavin's review suggests, the use or nonuse of rewards or other forms of external incentive is a potentially important variable that in part overlaps with cooperation-competition and in part is independent of it. Some approaches to cooperative learning include the use of extrinsic rewards (e.g., TeamsGames-Tournaments: Slavin, 1980), while others explicitly avoid it (e.g., group investigation: Sharan \& Hertz-Lazarowitz, 1980). Competition in educational settings usually involves extrinsic incentives, in the form of either rewards for progress toward a defined standard or goal or explicit comparisons of one's performance with that of 
others. Although some research on the effects of extrinsic rewards indicates that, at least under certain conditions, the use of external rewards tends to undermine intrinsic motivation (Lepper, 1983; Ryan, Connell, \& Deci, 1985), there is also evidence that, under some conditions, extrinsic incentives can promote intrinsic motivation. Rewards that emphasize success or competence, for example, given as symbols of task mastery, can actually enhance intrinsic motivation (Morgan, 1984). Furthermore, a vast body of behavioral research has shown that external reinforcement is effective for changing behavior (at least in the short term). Definitive conclusions about the effects of rewards in educational settings are not yet possible.

In this article we compare two elementary school programs that differ with respect to both task structures and incentive structures and we focus on the social, affective, and behavioral effects of these programs on students. The investigations described here grew out of an ongoing evaluation of a school intervention designed to promote children's prosocial development (CDP, defined below) that was being conducted in several schools in one California school district. The opportunity arose to compare the effects of this intervention program-which stressed cooperative activities, intrinsic motivation, and student autonomy-with a distinctly different program in another district that stressed measurable goals and standards and a competitive external reward system for student activity (EXS, denned below).

\section{The Programs}

The school programs or approaches being compared were located in two suburban, middle- to upper-middle-class California school districts of medium size. The schools in both districts were characterized by high achievement scores, moderate to high housing prices, low scores on poverty indices (e.g., number of Aid to Families with Dependent Children [AFDC] families), and rel- atively few minority students. Table 1 presents information comparing student achievement on the California Assessment Program (CAP) test battery and on parental demographics for the EXS and CDP schools.

In comparing the EXS classrooms with all three CDP program classrooms (the experimental groups), certain demographic differences appear. The percentage of parents with B.A. degrees and the percentage of parents working as executives, professionals, and managers are somewhat higher for the EXS classrooms. The possible effects of these differences will be discussed in the results section. The other demographic indices are similar.

In contrast, the achievement (CAP) scores for both groups are generally in a very high range, with the CDP schools slightly higher at the third-grade level and the EXS school slightly higher at the sixthgrade level. We will describe the programs in each district separately.

\section{District 1}

This district has had one superintendent for 30 years and during that time has maintained an emphasis on motivation, accountability, and commitment to the philosophy of school-based management by implementing a management system based on competition. The competition model encompasses five key functions prevalent throughout the district, schools, and classrooms:

1. establishing specific, measurable goals, standards, and performance indicators in five areas (curricular, cocurricular, athletics, community involvement, and school management);

2. conducting frequent, systematic monitoring and assessment of performance;

3. measuring and rating school performance relative to the goals and publishing the results;

4. recognizing units (Red and Blue, each composed of half the schools in the dis- 
TABLE 1. Baseline Demographic and Achievement Data for EXS and CDP Schools

Demographic Data

\begin{tabular}{|c|c|c|c|c|c|}
\hline \multicolumn{2}{|l|}{ Variable } & $\begin{array}{l}\text { Comparison } \\
\text { Classrooms } \\
(\mathrm{N}=6)\end{array}$ & \multicolumn{2}{|c|}{$\begin{array}{l}\text { CDP Classrooms } \\
(\mathrm{N}=8)\end{array}$} & $\begin{array}{l}\text { EXS Classrooms } \\
\qquad(\mathrm{N}=3)\end{array}$ \\
\hline \multicolumn{2}{|c|}{$\begin{array}{l}\text { Living in district for } 6 \text { years or } \\
\text { more }\end{array}$} & 30 & \multicolumn{2}{|c|}{22} & 32 \\
\hline \multicolumn{2}{|c|}{$\begin{array}{l}\text { Executives, professionals, } \\
\text { managers }\end{array}$} & 51 & \multicolumn{2}{|c|}{61} & 80 \\
\hline \multicolumn{2}{|c|}{ Parents with B.A. degree or more } & 56 & \multicolumn{2}{|c|}{55} & 73 \\
\hline \multicolumn{2}{|l|}{ One-parent families } & 6.5 & \multicolumn{2}{|c|}{2.5} & 4.5 \\
\hline \multicolumn{6}{|c|}{ Achievement Data } \\
\hline \multicolumn{6}{|l|}{ California Assessment } \\
\hline Program (CAP)" & Mean & Range & Mean & Range & Mean $^{b}$ \\
\hline \multicolumn{6}{|l|}{ Grade 3: } \\
\hline Reading & 92 & $90-96$ & 87 & $72-97$ & 85 \\
\hline Writing & 94 & $92-97$ & 90 & $84-98$ & 91 \\
\hline Math & 92 & $79-98$ & 88 & $82-99$ & 79 \\
\hline \multicolumn{6}{|l|}{ Grade 6: } \\
\hline Reading & 84 & $69-91$ & 84 & $79-88$ & 92 \\
\hline Writing & 88 & $83-91$ & 87 & $81-91$ & 90 \\
\hline Math & 88 & $66-93$ & 89 & $85-96$ & 97 \\
\hline
\end{tabular}

NOTE.-The CDP data were gathered from parents of students when they were in kindergarten. The EXS students were added to the study when they were in second grade; data shown for that shcool were gathered during that school year.

- These data are reported in percentiles.

The CAP scores are reported by grade level within schools. Thus no range is reported for the EXS school.

trict), schools, classes, and individuals for goal achievement; and

5. supporting school personnel in their efforts to achieve the goals.

Virtually all aspects of the school program are included in the competition model-from academic achievement to athletic performance, attendance, and vandalism. The use of points accumulated for each competition area and rewards for successful performance in each area is the primary means of communicating priorities and expectations. This system of setting standards and awarding points and ratings was not designed to promote individual or group success at the expense of others but, rather, to emphasize that success (individual, class, team, unit) is dependent on the success of each participant. Thus, although competi- tion between individuals does occur and is assessed, cooperation, support, and interdependence within the various groupings and competition between the various groupings are emphasized. Results of the competition model are visible in the high student participation in school activities, with $90 \%$ of all students participating in at least one of the 17 competition areas; an average daily attendance rate of $94 \%$; low incidence of vandalism and burglary; and high levels of parental participation and support.

The elementary school that was chosen as the assessment site in this competitive district contained about 600 students. It focused, as did the entire district, on the following major components in its goal to achieve the expected high standards: direct instruction, diagnostic/prescriptive teaching, high achievement standards, interclass 
academic competitions, high participation in competitive cocurricular activities, and recognition for high performance in each activity and at each level.

Student progress at this school was monitored and feedback provided through weekly interclass academic competitions, district competition results, and observations. One hundred percent of the uppergrade students in this competitive school participated in at least one of the school's competitions, with $93 \%$ of the school's sixth graders participating in school-sponsored clubs, special observances, or student government. Approximately $40 \%$ of the uppergrade students (fourth through sixth grades) participated in the interscholastic athletic program involving tackle football, volleyball, cross-country, basketball, wrestling, baseball, paddle tennis, and track. Students were given awards for participating and for outstanding performance on an individual and group basis, each based on accumulated points.

In this article we refer to the program in this school as the "external standards" (EXS) program. Further information about this program and its effects is available from the first author.

\section{District 2}

This district does not have as strong and pervasive an educational philosophy as does District 1. Consequently, there is probably more variability among schools and teachers with respect to management styles, educational goals, and the use of incentives than there is in District 1.

Six of the 13 elementary schools in this district have been involved in a long-term project designed to promote children's prosocial development-the Child Development Project (CDP). These six schools were divided into two equivalent groups of three. One of the groups was randomly selected to form a program (experimental) group and has been implementing over the past several years a specific educational intervention program developed through this proj- ect; the other group of three schools forms a comparison (control) group and has received no special intervention. Both the CDP program (experimental) schools and the EXS school were compared to these comparison (control) schools for research purposes.

The program's goals are to help children develop an internal commitment to important values and norms, such as responsibility, concern and respect for others, and helpfulness and to enhance various collaborative and interpersonal skills and related attitudes and motives. The program assumes that this can best be done by providing children the experience of participating in a community of mutually concerned teachers and students where prosocial values are emphasized and exemplified and where children have opportunities to think about and act on those values and to learn about the feelings, motives, and perspectives of others. The program consists of five interrelated components.

1. Developmental discipline. This is a child-centered approach to classroom management that attempts to create a sense of community among students so that they will feel personally committed to the classroom's norms and values. This is done by having students participate in setting the class rules early in the year, through periodic class meetings in which problems are dealt with and resolved through mutual discussion, and through provision of other opportunities for student input, autonomy, and participating in decision making. The use of rewards and punishments is minimized, and strong emphasis is placed on helping children to see intrinsic reasons for performing academic tasks and for interacting positively with one another.

2. Cooperative learning. Students work collaboratively in small groups on tasks with both academic and social goals. The social skills required for effective collaboration are discussed before and after each group activity, and the underlying values that are reflected in those skills (e.g., re- 
spect, consideration for others, responsibility) are emphasized. Group members are assigned specific rotating roles (e.g., facilitator, recorder) to ensure that each will have a broad experience and to minimize the effects of status differences (as discussed by Cohen, 1987). Children are encouraged to help one another and to try to solve their own problems (academic or social) before seeking help from the teacher.

3. Helping activities. Students are encouraged to help one another in the classroom and to provide help to the class as a whole (e.g., through performing chores), to the school (e.g., through working on school maintenance or beautification projects), and to the community. The schools have also initiated "buddies" programs whereby older students give help and companionship to younger students.

4. Social-understanding activities. Various activities are designed to enhance children's understanding of others-including other students in the classroom and people of other ages, of other cultures, and in diverse conditions. Literature is the primary means for accomplishing this. Books are chosen that present the motives, intentions, and values of different characters in varied settings, and teachers lead discussions that focus on exploring these. Teachers also make use of spontaneous classroom occurrences (e.g., interstudent conflicts) to help children to understand differences in goals, perspectives, and intentions.

5. Highlighting prosocial values. In a sense, this should not be considered a separate component since an emphasis on prosocial values permeates each of the other components. The literature selected for social-understanding activities, for example, also exemplifies the operation of prosocial values; these are pointed out and discussed. Teachers also make occasional comments that focus attention on the operation of prosocial values in the classroom and emphasize their importance.

For further information about this program and its effects, see Battistich, Watson,
Solomon, Schaps, and Solomon (in press); Solomon, Watson, Schaps, Battistich, and Solomon (1990); and, Watson, Schaps, Battistich, Solomon, and Solomon (1989).

\section{Procedures}

\section{Design}

The evaluation of the CDP intervention project (District 2) has focused on a longitudinal cohort of children who entered kindergarten in the fall of 1982 . The program was provided to children of that cohort (along with their newly entering classmates) in each successive grade as they moved through the elementary grades in three schools. Children in three parallel schools in the same district, in which the district's ordinary educational program has been provided, have served as a comparison group. An initial set of assessments was undertaken in all six District 2 schools in the spring of 1982 (before the start of the program). These established that children in the two sets of District 2 schools (the CDP program and comparison schools) were essentially undifferentiated before the program began. Further assessments have been made toward the end of each subsequent year in both sets of schools.

During the years when the CDP cohort children were in grades 2-5, many of the same assessments were also used with classrooms and children at the same grade levels in the selected EXS school from District 1 . The children in this school did not, therefore, participate in the baseline comparison assessment conducted in District 2 in the spring of 1982. The sociodemographic similarity of the two districts, however, leads us to assume that students were probably similar in numerous other respects.

The sample from the single EXS school (District 1) involved three classrooms and about 60 students each year in grades 2-4; in grade 5 the sample was increased to 90 students. The three CDP program schools involved seven or eight classrooms during each of the years that the cohort was in 
grades 2-4, with about 160 students; in grade 5 , the sample was reduced to one school with four classrooms and 80 students. The three comparison schools involved six or seven classrooms during the years when the cohort was in grades 2-4, with about 145 students; and one school with 43 students in two classrooms in the fifth-grade year. (The numbers represent the children who received parental permission for participation in the research.)

\section{Assessments}

Classroom activities, with a focus on the five components of the CDP program, were assessed with a structured classroom observation system, teacher questionnaires, student questionnaires, and a portion of a student interview used in third grade. Teachers' perceptions of school climate were obtained from questionnaires. Students' interpersonal behavior was assessed during third-grade classroom observations and in a series of structured small-group activities (four-person tasks in grades 2 and 4 , dyadic tasks in grade 3). Students' social skills, motives, perceptions, and attitudes were assessed with interviews and, for grade 3 and above, with questionnaires.

Because the two districts were about 160 miles apart, it was not possible to have the classroom observations, interviews, or small-group tasks conducted by the same researchers in both. Coding of audiotapes of the interviews conducted in both districts, and of videotapes of children's behavior in the small-group tasks conducted in both, was performed by common groups of coders. Several between-district training sessions and other meetings were held each year to try to keep classroom observation category definitions and the interview and task-administration procedures as similar as possible across districts, but differences were discovered in the administration of some of the tasks and in some of the observation procedures (including observations of the fourth-grade classrooms). Corrections of these were made when possible; in other instances tasks or observation variables found to be noncomparable were eliminated from the analyses (e.g., only the third-grade classroom observations were used in the analyses reported here).

Teacher questionnaire. Goals of teachers in each program were assessed with questionnaires administered in the spring of each academic year. One section of the questionnaire asked the teachers to rate the importance of 30 possible goals of teaching; these were later reduced to a set of eight more general goals on the basis of both empirical and conceptual criteria. These eight scales represented the importance teachers placed on promoting students' (1) self-assurance, (2) social competence, (3) cognitive skill, (4) subject-matter mastery, (5) diligence/compliance, (6) general orientation to learning, (7) maturity, and (8) curiosity/ creativity. Another set of items asked about school climate. Also included in the questionnaire was a scale assessing teachers' control ideology, adapted from one developed by Deci, Schwartz, Sheinman, and Ryan (1981).

Classroom observations. Each of the classrooms in this study was observed during eight visits throughout the school year. Each observation consisted of a 2-hour visit during which a team of two observers watched the class for a series of 2-minute periods and then marked all of the observation-form categories that had occurred during each 2 -minute period. Observers focused on the teacher during half the periods and on groups of students during the other half. A rating system, used to make global assessments of various aspects of classroom activity, was filled out after the end of each observation visit.

A series of scales and subscales was derived from these data. Five of them represented the five CDP program components: (1) cooperative activities and emphasis, (2) developmental discipline, (3) helping activities and emphasis, (4) social-understanding activities, and (5) highlighting prosocial values. Four subscales of develop- 
mental discipline were also focused on on separately: (1) use of external control, (2) provision for student autonomy, (3) teacher sympathy-acceptance, and (4) teacher punitiveness. Scales that represented the teacher's emphasis on competitive activities and general competence were also derived. The reliabilities calculated, using Cronbach's alpha, ranged from .60 to .96 and averaged .79 for the teacher behavior and classroom activity scores.

Student interpersonal behavior. Student interpersonal data were collected in two ways: the classroom observations described previously focused on students' positive and negative behavior and on their spontaneous helping and harmoniousness. Students' interpersonal orientation and understanding were assessed through individual student interviews (assessing each child's approach to interpersonal conflict resolution, social understanding, reactions to transgressions, tendencies to provide help to others at some cost to self, social desirability, donating behavior, giving help to an adult, and perceptions of the relative value of helping others achieve something vs. personal achievement), group questionnaires, and small-group tasks (four-person or dyadic). All reliabilities were calculated using Cronbach's alpha. The reliabilities for the third-grade student classroom interpersonal behaviors ranged from .54 to .90 and averaged .74; reliabilities for third-grade individual interview scores ranged from .47 to .87 and averaged .65; and reliabilities for the fourth-grade individual interviews ranged from .54 to .90 and averaged .74. Detailed information about the classroom observation procedures, the small-group tasks, and the student interviews and questionnaires has been previously described by Deer, Solomon, Watson, and Solomon (1988); Solomon, Watson, Delucchi, Schaps, and Battistich (1988); Stone, Solomon, Tauber, and Watson (1989); and Tauber, Rosenberg, Battistich, and Stone (1989).

\section{Results and Discussion}

The instruments we have described, some administered multiple times over the 4-year period, produced a substantial amount of data. Detailed tables presenting the findings obtained with each instrument during each year are available from the authors on request. In this article, we discuss the findings we believe are most likely to be stable and meaningful. Some variables were assessed only once, others on two or more occasions. We focus our summary on findings that showed significant contrasts between groups and were obtained at least twice, with no reversals. Additional findings that were consistent with these are also described. Although this approach bypasses a number of findings based on measures that were assessed only once and thus are incapable of replication within this body of data, we believe the repeated findings constitute the best and most stable evidence concerning the implementation and effects of these programs.

\section{School Climates}

Each of the teacher questionnaires, administered at the end of each school year, included a set of questions about perceptions of school climate. Although the climates were seen as generally positive in all three sets of schools, several variables derived from these items showed repeated differences between groups. The EXS teachers were more likely than the CDP program teachers to see their school as having a traditional academic emphasis and a businesslike task orientation, but also as being more creative and innovative. They saw the principal as more supportive and accessible, the parents as more involved in the school, teacher-student relations as more positive, and the general school atmosphere as more pleasant. The teachers also reported more pressure on them to perform well. The impression of the EXS school conveyed by these findings is of an active, involved, taskoriented principal and faculty, in a lively, controlled, and demanding setting. 
Classroom Environments and

\section{Activities}

Data from several sources (classroom observations, teacher questionnaires, student questionnaires, student interviews) showed differences among the school groups that generally corresponded with the intentions of the different educational programs.

Incentive structures. Teachers in the EXS school reported much more use of awards and prizes and were more likely to state that they used a penalty system (point removal) for discipline. They more frequently gave rewards to individuals and to groups for good performance; spent more time arranging for these reward and penalty structures; and used rewards at more levels (e.g., within-class groups, classrooms, grade levels, whole school).

Task structures. Teachers in the EXS school also reported greater use of interstudent, intergroup, and interschool competitive activities, while those in the CDP program schools reported more frequent use of cooperative groups (i.e., groups with group products, and those in which members helped each other with their individual tasks). The greater frequency of cooperative groups in the CDP program classrooms also was indicated by the classroom observations and the student reports. Students in the CDP classrooms reported more collaborative interaction in their groups and were also more likely to say (in the third-grade interview) that their group activities involved academics in which they got help with problems. EXS classrooms used group work for academics less frequently.

Students in the two programs gave different responses to questions about why teachers had them work in groups. The CDP third-grade students stated that teachers had them work in groups to prepare for adulthood and to learn to be cooperative, work together, and understand each other, whereas EXS third-grade students stated that teachers had them work in groups to be helpful and kind and to get things done quickly and efficiently. Interestingly, although most of the students in all schools said that they liked working in groups (third-grade interview), EXS students were more likely to give as reasons that the group work was fun and made them feel good to be with friends, probably because these groups were used more for games and play activities in the EXS school. When asked about their goals for group activities, CDP program teachers scored higher on the goal of helping students learn social skills, while EXS teachers scored higher on the goal of helping students experience group competition.

When asked what they did not like about working in groups, CDP program students were more likely to mention problems in getting work finished (because of distractions, talking, fooling around, and work not getting finished), while EXS students were more likely to say that too much work was expected due to its being a group effort.

Classroom atmosphere. As shown in Table 2, CDP teachers made greater use of most of the five major components of their program (cooperative and social-understanding activities, highlighting prosocial values, and providing for student autonomy). They also gave students more opportunity to exercise autonomy-through participating in the development of class rules, participating in class meetings and decision making, and determining their own methods of learning and problem solving. The CDP program students similarly reported greater participation in classroom decision making (fifth-grade questionnaire). Activities designed to promote students' social understanding were reported to be more frequent in the CDP program classrooms both by the classroom observers and by teachers in their responses to questionnaires.

Although teachers in both of the programs stressed the importance of positive student behavior, this appears to have been denned more as diligence, compliance, and respect for authority in the EXS school, and 
TABLE 2. Third-Grade Teacher Behavior and Classroom Activity Scores, by School Status

\begin{tabular}{|c|c|c|c|c|}
\hline Variable & $\begin{array}{l}\text { Comparison } \\
\text { Classrooms } \\
(\mathrm{N}=6)\end{array}$ & $\begin{array}{c}\text { CDP } \\
\text { Classrooms } \\
(N=8)\end{array}$ & $\begin{array}{c}\text { EXS } \\
\text { Classrooms } \\
(\mathrm{N}=3)\end{array}$ & $\begin{array}{c}\text { ANOVA F-Values } \\
\text { (Scheffe's post hoc } \\
\text { F-Values) }\end{array}$ \\
\hline \multicolumn{5}{|c|}{$\begin{array}{l}\text { Cooperative activities and } \\
\text { emphasis: }\end{array}$} \\
\hline $\mathrm{X}$ & 45.11 & 56.50 & 42.44 & $4.82 *$ \\
\hline $\mathrm{S}$ & 11.10 & 6.84 & 1.25 & $\begin{array}{c}(3.29 * \text { CDP }>\text { Comp, } \\
3.19 * \text { CDP }>\text { EXS })\end{array}$ \\
\hline \multicolumn{5}{|c|}{ Developmental discipline: } \\
\hline $\mathrm{X}$ & 45.80 & 54.45 & 46.53 & 1.62 \\
\hline$S$ & 12.34 & 8.26 & 5.52 & \\
\hline \multicolumn{5}{|c|}{$\begin{array}{l}\text { Helping activities and } \\
\text { emphasis: }\end{array}$} \\
\hline $\mathrm{X}$ & 44.99 & 54.44 & 48.18 & 1.74 \\
\hline $\mathrm{S}$ & 5.28 & 10.32 & 14.09 & \\
\hline \multicolumn{5}{|c|}{ Social-understanding activities: } \\
\hline $\mathrm{X}$ & 44.49 & 56.94 & 42.49 & $5.97 *$ \\
\hline $\mathrm{S}$ & 7.23 & 8.93 & 4.70 & $\begin{array}{c}\left(4.31^{*} \text { CDP }>\text { Comp, }\right. \\
\left.3.69{ }^{h} \text { CDP }>\text { EXS }\right)\end{array}$ \\
\hline \multicolumn{5}{|c|}{ Highlighting prosocial values: } \\
\hline $\mathrm{X}$ & 42.19 & 55.19 & 51.78 & $4.10 *$ \\
\hline $\mathrm{S}$ & 9.45 & 8.96 & .50 & $(4.02 * \mathrm{CDP}>\mathrm{Comp})$ \\
\hline \multicolumn{5}{|c|}{$\begin{array}{l}\text { Total CDP program } \\
\text { approximation: }\end{array}$} \\
\hline $\mathrm{X}$ & 42.93 & 57.14 & 45.11 & $6.66^{* *}$ \\
\hline $\mathrm{S}$ & 9.32 & 7.31 & 2.41 & $(5.91 * \mathrm{CDP}>\mathrm{Comp})$ \\
\hline \multicolumn{5}{|c|}{$\begin{array}{l}\text { Competitive activities and } \\
\text { emphasis: }\end{array}$} \\
\hline $\mathrm{X}$ & 53.26 & 47.02 & 51.41 & $<1.0$ \\
\hline $\mathrm{S}$ & 10.97 & 9.96 & 9.06 & \\
\hline \multicolumn{5}{|c|}{ Use of external control: } \\
\hline $\mathrm{X}$ & 53.61 & 46.49 & 52.14 & $<1.0$ \\
\hline $\mathrm{S}$ & 14.61 & 6.64 & 4.14 & \\
\hline \multicolumn{5}{|c|}{$\begin{array}{l}\text { Provision for student } \\
\text { autonomy: }\end{array}$} \\
\hline $\mathrm{X}$ & 44.44 & 57.14 & 42.08 & $6.68 * *$ \\
\hline $\mathrm{S}$ & 9.24 & 7.28 & 3.22 & $\begin{array}{c}(4.73 * \mathrm{CDP}>\mathrm{Comp}, \\
\left.4.22^{* 1} \mathrm{CDP}>\mathrm{EXS}\right)\end{array}$ \\
\hline \multicolumn{5}{|c|}{ Teacher sympathy, acceptance: } \\
\hline $\mathrm{X}$ & 46.72 & 52.13 & 50.89 & $<1.0$ \\
\hline $\mathrm{S}$ & 11.97 & 9.15 & 9.88 & \\
\hline \multicolumn{5}{|c|}{ Teacher punitiveness: } \\
\hline $\mathrm{X}$ & 50.44 & 48.93 & 51.96 & $<1.0$ \\
\hline $\mathrm{S}$ & 10.59 & 11.76 & 4.95 & \\
\hline \multicolumn{5}{|c|}{ Teacher competence: } \\
\hline$X$ & 53.67 & 49.26 & 44.63 & $<1.0$ \\
\hline $\mathrm{S}$ & 7.19 & 12.06 & 8.70 & \\
\hline
\end{tabular}

NOTE.-All scores represented in this table are T-scores. Comp $=$ comparison group. $y<.10$.

$* p<.05$.

$* * \mathrm{p}<.01$.

more as interpersonal helpfulness, concern, and understanding in the CDP program schools. Furthermore, the means by which teachers tried to achieve these and other goals were distinctly different. The EXS school did so through rewards and penalties (point removal), direct teacher control, and competitions; the CDP program schools through an emphasis on student autonomy, cooperative activities, and interpersonal understanding. It is notable that much of the competitive activity in the EXS school ap- 
peared to be intergroup or interschool competition, implying a good bit of cooperation within the groups. In this respect, the system appears to be similar to one current approach to academic cooperative learning (Slavin, 1980) that also involves intragroup cooperation combined with intergroup competition. Teachers in EXS classrooms, however, did not regularly use cooperative groups for academics. It is interesting that the fifth-grade students in both the EXS and CDP programs stated greater liking for their classes than did those in the CDP comparison schools.

\section{Effects on Students}

Although a large number of student outcome effects were found, it should be noted that there also were a number of variables on which the comparison-group students did not differ significantly and consistently from those in either of the two program groups. Among these are concern for others, liking for school, overall positive group orientation (third grade); social competence, competitive orientation, perceived pleasantness of class, and achievement motivation (all in fourth grade); and much of the behavior observed over the years in the four-person and dyadic tasks (e.g., collaboration on tasks, engagement in discussions, helping behavior). Moreover, many of the program effects that were found were somewhat scattered; relatively few significant findings were repeated on two or more occasions. The consistent trends are described below, taken in part from Tables 3 and 4 , showing results for student attitudes derived from the group questionnaires in third and fourth grades and, in part, from individual student interviews and the fifthgrade student questionnaire.

Self-esteem. Students' self-esteem was assessed twice-in both the third-grade (1986) and fourth-grade (1987) student questionnaires. Students in the EXS school scored significantly higher than the comparison students on variables related to academic self-esteem, general self-esteem, and total self-esteem (a mean of academic and general items) at the third-grade level and also significantly higher on total selfesteem than did CDP program students. At the fourth grade, EXS students scored significantly higher than either of the other groups on the general self-esteem variable.

Motivation. Extrinsic-intrinsic motivation for prosocial acts was also assessed twice-once in the fourth-grade (1987) student interview (with an open-response format), and once in the fifth-grade (1988) student questionnaire (with a fixed-response format). Students in the EXS school scored higher (ps $<.01,001$; if $=06, .07$ ) than either group of CDP schools on the measures of extrinsic prosocial motivation, and scored significantly lower $(p<.001, .001$, $\left.\mathrm{J} ?^{2}=.04, .06\right)$ than either CDP group on the combined proportions of intrinsic reasons for prosocial actions at each grade level (though not on total intrinsic reasons for prosocial acts). Intrinsic academic motivation was also assessed in the fifth-grade questionnaire but did not show significant differences between the programs, although students in each program scored higher than children in the comparison schools. Students in the EXS school were thus generally more likely to see their own and their classmates' prosocial behavior as motivated by extrinsic concerns (e.g., rewards, penalty points, and authority demands), whereas those in the CDP program classrooms were more likely to see their behavior as motivated by intrinsic concerns (e.g., inherent value of the activity, relevance to moral concerns or long-term goals).

Interpersonal behavior. Third-grade classroom observations (summarized in Table 5) indicated that students' interpersonal classroom behavior was more harmonious, spontaneously helpful, and generally supportive and friendly in the CDP program schools than in the EXS school. Although these differences were not statistically significant, due to the very small sample size involved in these comparisons, the effect 
TABLE 3. Third-Grade Mean Attitudinal Scores, by School Status Attitudinal Scores, by School Status

\begin{tabular}{|c|c|c|c|c|}
\hline Variable & $\begin{array}{l}\text { Comparison } \\
\text { Students } \\
(\mathrm{N}=90)\end{array}$ & $\begin{array}{c}\text { CDP } \\
\text { Students } \\
(\mathrm{N}=166)\end{array}$ & $\begin{array}{l}\text { EXS } \\
\text { Students } \\
(\mathrm{N}=61)\end{array}$ & $\begin{array}{c}\text { ANOVA F-Values } \\
\text { (Scheffe's post hoc } \\
\text { F-Values) }\end{array}$ \\
\hline \multicolumn{5}{|c|}{ Concern for others: } \\
\hline $\mathrm{X}$ & 1.76 & 1.86 & 1.75 & 1.85 \\
\hline $\mathrm{S}$ & .48 & .49 & .51 & \\
\hline \multicolumn{5}{|c|}{ Liking for group activities: } \\
\hline $\mathrm{X}$ & 2.39 & 2.38 & 2.52 & $2.51 *$ \\
\hline $\mathrm{S}$ & .47 & .45 & .39 & (N.S.y \\
\hline \multicolumn{5}{|c|}{ Value of groups for learning: } \\
\hline $\mathrm{X}$ & 2.20 & 2.20 & 2.09 & $<1.0$ \\
\hline $\mathrm{S}$ & .58 & .55 & .53 & \\
\hline \multicolumn{5}{|c|}{$\begin{array}{l}\text { Overall positive group } \\
\text { orientation: }\end{array}$} \\
\hline $\mathrm{X}$ & 2.35 & 2.34 & 2.43 & 1.15 \\
\hline $\mathrm{S}$ & .43 & .41 & .34 & \\
\hline \multicolumn{5}{|c|}{ Academic self-esteem: } \\
\hline $\mathrm{X}$ & 2.21 & 2.29 & 2.38 & $2.48^{*}$ \\
\hline $\mathrm{S}$ & .48 & .44 & .47 & $(2.50 *$ EXS $>$ Comp $)$ \\
\hline \multicolumn{5}{|c|}{ General self-esteem: } \\
\hline $\mathrm{X}$ & 2.29 & 2.34 & 2.49 & $3.02 *$ \\
\hline $\mathrm{S}$ & .54 & .47 & .47 & $(3.00 *$ EXS $>$ Comp $)$ \\
\hline \multicolumn{5}{|c|}{ Total self-esteem: } \\
\hline $\mathrm{X}$ & 2.25 & 2.31 & 2.44 & $3.89^{*}$ \\
\hline $\mathrm{S}$ & .44 & .37 & .42 & $\begin{array}{c}\left(4.09^{* \prime} \mathrm{EXS}>\mathrm{Comp}\right. \\
\left.2.35^{\prime} \cdot \mathrm{EXS}>\mathrm{CDP}\right)\end{array}$ \\
\hline \multicolumn{5}{|c|}{ Competitive orientation: } \\
\hline $\mathrm{X}$ & 1.70 & 1.66 & 1.82 & $2.80 *$ \\
\hline $\mathrm{S}$ & .47 & .42 & .51 & $(2.77 * \mathrm{EXS}>\mathrm{CDP})$ \\
\hline \multicolumn{5}{|c|}{ Motive to help others learn: } \\
\hline $\mathrm{X}$ & 2.54 & 2.54 & 2.33 & $3.73 *$ \\
\hline$S$ & .51 & .54 & .62 & $\begin{array}{c}(2.67 * \text { Comp }>\text { EXS } \\
\left.3.28^{*} \text { CDP }>\text { EXS }\right)\end{array}$ \\
\hline \multicolumn{5}{|c|}{ Assertion responsibility: } \\
\hline $\mathrm{X}$ & 3.00 & 3.26 & 3.11 & $4.32 *$ \\
\hline $\mathrm{S}$ & .69 & .69 & .72 & $(4.10 *$ CDP > Comp) \\
\hline \multicolumn{5}{|c|}{ Willingness to compromise: } \\
\hline $\mathrm{X}$ & 3.35 & 3.35 & 3.19 & 1.74 \\
\hline $\mathrm{S}$ & .52 & .53 & .75 & \\
\hline \multicolumn{5}{|c|}{ Equality of representation: } \\
\hline $\mathrm{X}$ & 3.03 & 3.09 & 3.11 & $<1.0$ \\
\hline $\mathrm{S}$ & .63 & .57 & .63 & \\
\hline \multicolumn{5}{|l|}{ Empathy: } \\
\hline $\mathrm{X}$ & 1.68 & 1.60 & 1.47 & $12.88^{* * *}$ \\
\hline $\mathrm{S}$ & .23 & .25 & .26 & $\begin{array}{c}(3.03 * \text { Comp }>\text { CDP } \\
13.01 * * * \text { Comp }>\text { EXS } \\
6.12 * " ' \mathrm{CDP}>\mathrm{EXS})\end{array}$ \\
\hline \multicolumn{5}{|c|}{ Perceptual benevolence: } \\
\hline $\mathrm{X}$ & 1.75 & 1.79 & 1.76 & $<1.0$ \\
\hline $\mathrm{S}$ & .24 & .19 & .26 & \\
\hline
\end{tabular}

NOTE.-Comp = comparison group.

"The Scheffe's post hoc F-test is a conservative test. Occasionally no significant comparisons are found even though the overall $\mathrm{F}$ is significant.

$$
\begin{aligned}
& * p<.10 . \\
& * p<.05 . \\
& * * *<>01 . \\
& * * * p<.001 .
\end{aligned}
$$


TABLE 4. Fourth-Grade Mean Attitudinal Scores, by School Status

\begin{tabular}{|c|c|c|c|c|}
\hline Variable & $\begin{array}{l}\text { Comparison } \\
\text { Classrooms } \\
(N-\quad 6)\end{array}$ & $\begin{array}{c}\text { CDP } \\
\text { Classrooms } \\
(\mathrm{N}=8)\end{array}$ & $\begin{array}{c}\text { EXS } \\
\text { Classrooms } \\
(\mathrm{N}-3)\end{array}$ & $\begin{array}{l}\text { ANOVA F-Values } \\
\text { (Scheffe's post hoc } \\
\text { F-Values) }\end{array}$ \\
\hline \multicolumn{5}{|c|}{ Concern for others: } \\
\hline $\mathrm{X}$ & 2.06 & 2.01 & 2.15 & 1.61 \\
\hline $\mathrm{S}$ & .55 & .58 & .50 & \\
\hline \multicolumn{5}{|c|}{ Motive to help others learn: } \\
\hline $\mathrm{X}$ & 2.64 & 2.62 & 2.62 & $<1.0$ \\
\hline $\mathrm{S}$ & .41 & .41 & .47 & \\
\hline \multicolumn{5}{|c|}{ Competence to help others: } \\
\hline $\mathrm{X}$ & 2.39 & 2.34 & 2.34 & $<1.0$ \\
\hline $\mathrm{S}$ & .45 & .44 & .50 & \\
\hline \multicolumn{5}{|c|}{$\begin{array}{l}\text { Competence for social } \\
\text { interaction: }\end{array}$} \\
\hline $\mathrm{X}$ & 2.36 & 2.36 & 2.33 & $<1.0$ \\
\hline $\mathrm{S}$ & .33 & .33 & .41 & \\
\hline \multicolumn{5}{|c|}{$\begin{array}{l}\text { Competence in giving social } \\
\text { support: }\end{array}$} \\
\hline $\mathrm{X}^{\mathrm{sep}}$ & 2.45 & 2.44 & 2.43 & $<1.0$ \\
\hline $\mathrm{S}$ & .40 & .41 & .38 & \\
\hline \multicolumn{5}{|c|}{$\begin{array}{l}\text { Total self-perceived social } \\
\text { competence (mean of above } \\
\text { three scales): }\end{array}$} \\
\hline $\mathbf{X}$ & 2.40 & 2.38 & 2.37 & $<1.0$ \\
\hline S & .33 & .33 & .37 & \\
\hline \multicolumn{5}{|c|}{ General self-esteem: } \\
\hline $\mathrm{X}$ & 2.34 & 2.34 & 2.56 & $4.60 *$ \\
\hline $\mathrm{S}$ & .57 & .47 & .49 & $\begin{aligned}(4.01 * \mathrm{EXS} & >\mathrm{Comp} \\
4.05^{*} \mathrm{EXS} & >\mathrm{CDP})\end{aligned}$ \\
\hline \multicolumn{5}{|c|}{ Social self-esteem: } \\
\hline $\mathrm{X}$ & 2.49 & 2.42 & 2.47 & $<1.0$ \\
\hline $\mathrm{S}$ & .46 & .46 & .45 & \\
\hline \multicolumn{5}{|c|}{ Academic self-esteem: } \\
\hline $\mathrm{X}$ & 2.37 & 2.27 & 2.37 & 2.30 \\
\hline $\mathrm{S}$ & .44 & .44 & .45 & \\
\hline \multicolumn{5}{|c|}{$\begin{array}{l}\text { Total self-esteem (mean of above } \\
\text { three scales): }\end{array}$} \\
\hline $\mathrm{X}$ & 2.40 & 2.35 & 2.47 & 2.29 \\
\hline $\mathrm{S}$ & .40 & .36 & .39 & \\
\hline \multicolumn{5}{|c|}{ Empathy for negative events: } \\
\hline $\mathrm{X}$ & 1.55 & 1.55 & 1.61 & 1.07 \\
\hline $\mathrm{S}$ & .31 & .26 & .28 & \\
\hline \multicolumn{5}{|c|}{ Empathy for positive events: } \\
\hline $\mathrm{X}$ & 1.79 & 1.82 & 1.86 & 1.66 \\
\hline $\mathrm{S}$ & .27 & .23 & .25 & \\
\hline \multicolumn{5}{|c|}{$\begin{array}{l}\text { Total empathy (mean of above } \\
\text { two scales): }\end{array}$} \\
\hline $\mathrm{X}$ & 1.67 & 1.69 & 1.73 & 1.63 \\
\hline $\mathrm{S}$ & .25 & .21 & .23 & \\
\hline \multicolumn{5}{|c|}{ Desire to win: } \\
\hline $\mathrm{X}$ & 1.72 & 1.64 & 1.69 & $<1.0$ \\
\hline $\mathrm{S}$ & .56 & .48 & .53 & \\
\hline \multicolumn{5}{|c|}{ Desire to excel others: } \\
\hline $\mathrm{X}$ & 1.62 & 1.66 & 1.67 & $<1.0$ \\
\hline $\mathrm{S}$ & .47 & .46 & .52 & \\
\hline \multicolumn{5}{|c|}{$\begin{array}{l}\text { Total competitive orientation } \\
\quad \text { (mean of above two scales): }\end{array}$} \\
\hline $\mathrm{X}$ & 1.68 & 1.65 & 1.68 & $<1.0$ \\
\hline $\mathrm{S}$ & .46 & .41 & .47 & \\
\hline \multicolumn{5}{|c|}{ Liking for school: } \\
\hline $\mathrm{X}$ & 1.88 & 1.82 & 1.91 & 1.15 \\
\hline $\mathrm{S}$ & .46 & .48 & .39 & \\
\hline
\end{tabular}


TABLE 4. Continued

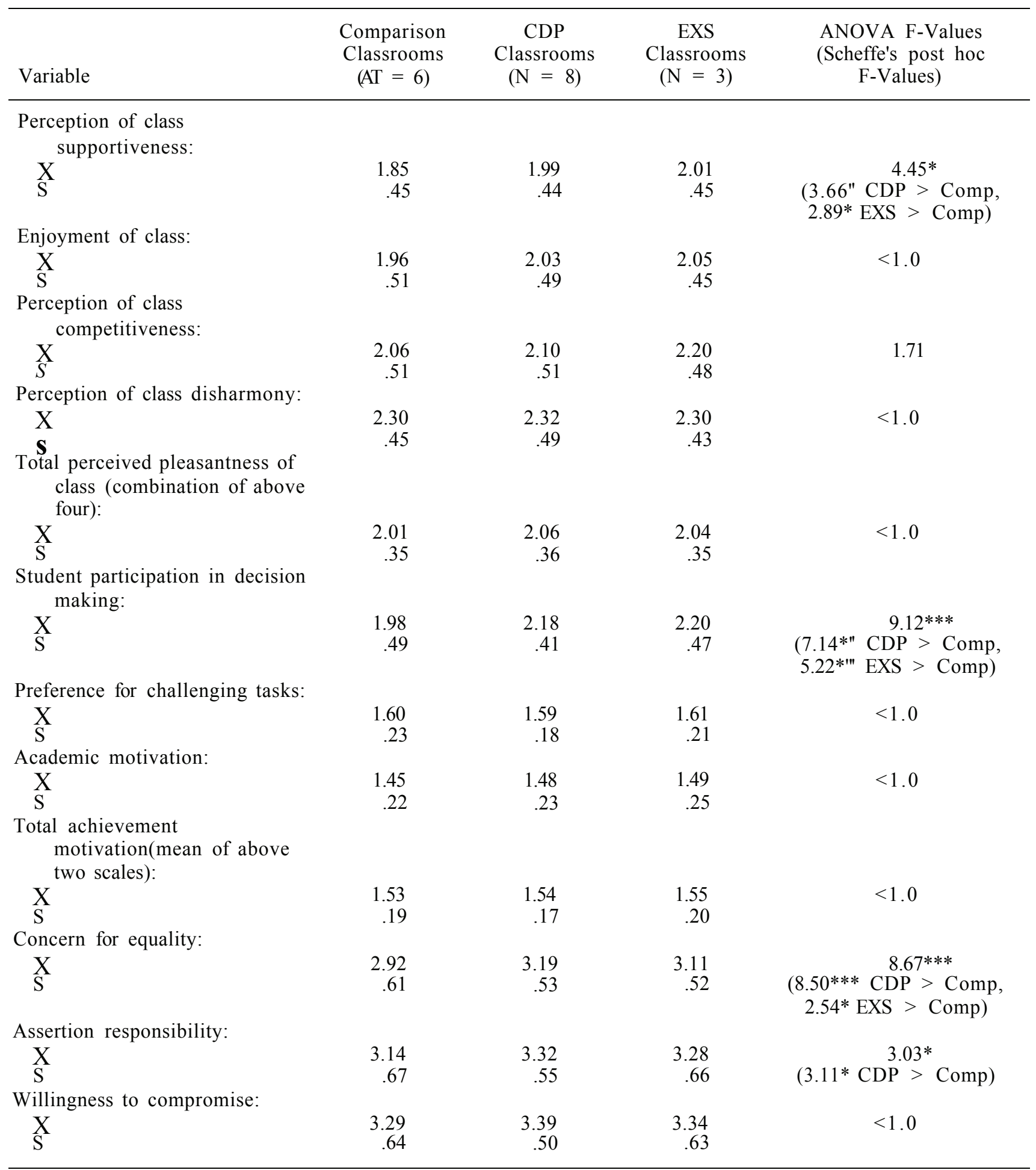

NOTE. - Comp $=$ comparison group.

$y<.10$.

${ }^{*} p<.05$.

$* * \mathrm{p}<.01$.

$* * * \mathrm{p}<.001$

sizes were substantial $\left(17^{2}=.35, .15\right.$, and .29 , respectively). Students in the CDP program schools also saw their classrooms as more harmonious and their classmates as more supportive (fifth-grade, but not fourth-grade, student questionnaire), while CDP program teachers saw less informal competition in their classrooms than teach- 
TABLE 5. Third-Grade Student Classroom Interpersonal Behavior, by School Status

\begin{tabular}{|c|c|c|c|c|}
\hline Variable & $\begin{array}{c}\text { Comparison } \\
\text { Classrooms } \\
(\mathrm{N}=6)\end{array}$ & $\begin{array}{c}\text { CDP } \\
\text { Classrooms } \\
(\mathrm{N}=8)\end{array}$ & $\begin{array}{c}\text { EXS } \\
\text { Classrooms } \\
(\mathrm{N}=3)\end{array}$ & $\begin{array}{c}\text { ANOVA } F \text {-Values } \\
\text { (Scheffe's post hoc } \\
F \text {-Values) }\end{array}$ \\
\hline \multicolumn{5}{|c|}{ Positive behavior: } \\
\hline $\mathrm{X}$ & 46.18 & 55.08 & 44.10 & \multirow[t]{2}{*}{2.32} \\
\hline $\mathrm{S}$ & 8.34 & 9.20 & 11.42 & \\
\hline \multicolumn{5}{|c|}{ Negative behavior: } \\
\hline $\mathrm{X}$ & 46.03 & 51.91 & 52.83 & \multirow[t]{2}{*}{.71} \\
\hline $\mathrm{S}$ & 8.71 & 6.27 & 19.97 & \\
\hline \multicolumn{5}{|c|}{$\begin{array}{l}\text { Proportion of positive } \\
\text { behavior: }\end{array}$} \\
\hline $\mathrm{X}$ & .69 & .66 & .56 & \multirow[t]{2}{*}{1.37} \\
\hline $\mathrm{S}$ & .09 & .13 & .12 & \\
\hline \multicolumn{5}{|c|}{ Spontaneous helping: } \\
\hline X & 49.55 & 52.90 & 43.17 & \multirow[t]{2}{*}{1.05} \\
\hline$S$ & 6.75 & 11.63 & 10.41 & \\
\hline \multicolumn{5}{|c|}{ Harmoniousness: } \\
\hline $\mathrm{X}$ & 51.75 & 52.69 & 39.33 & \multirow[t]{2}{*}{2.47} \\
\hline $\mathrm{S}$ & 8.66 & 10.02 & 7.21 & \\
\hline
\end{tabular}

NOTE.-All scores represented in this table are T-scores.

ers in either of the other two groups (second-grade teacher questionnaire).

With regard to small-group task settings observed outside the classroom, EXS students scored higher on a general measure of affiliation across all tasks administered in the third grade, while the CDP program students scored higher on a general measure of helping behavior during these same tasks. In general, however, over this 3-year period of assessment, student prosocial behavior in these small-group task settings was not significantly differentiated among the three school settings.

Statistical considerations. The meaning of these observed effects on students is complicated by statistical power differences. Two of the sets of repeated-outcome findings described (concerning self-esteem and extrinsic prosocial motivation) were based on individual-level student data involving fairly large sample sizes that produced differences that were statistically significant (ranging from $p<.10$ to $p<.0001$ ) but represented small to moderate effects (between $2 \%$ and $7 \%$ of the variance). The statistically nonsignificant group differences for students' interpersonal behavior in the classroom observed during the third grade, in contrast, were class-level data with very small, unequal sample sizes. Although the effect sizes of these differences are inflated due to the low standard deviations typically found for class-level analyses, they are still substantial (ranging from $15 \%$ to $35 \%$ of the variance). In sum, the observed differences in student classroom behavior are relatively large but possibly unstable, whereas the differences in self-esteem and extrinsic prosocial motivation are stable but small to moderate in effect.

Possible effects of demographic differences. As shown earlier (Table 1), the EXS school, although generally similar to the CDP schools, seemed to be at a higher socioeconomic status (SES) level. To assess the possibility that some of the findings may be due to this demographic difference rather than to differences in the school programs, a parallel set of analyses was conducted that compared the EXS school to the most similar single CDP program and CDP comparison schools. The demographic data for these schools were parents with B.A. degrees: $\mathrm{EXS}=73 \%, \mathrm{CDP}$ program $=74 \%$, CDP comparison $=59 \%$, parents working as executives, professionals, or managers: $\mathrm{EXS}=80 \%, \mathrm{CDP}$ program $=85 \%, \mathrm{CDP}$ 
comparison $=58 \%$. Results of these new analyses, which included all of the same variables as in the larger analyses, were very similar and in the same direction as those presented in this article. This suggests that the findings presented are not attributable to differences in demographic characteristics.

\section{Conclusion}

The measures of classroom activities indicate that the programs were actually different in ways consistent with their intentions: EXS classrooms showed more use of external controls in the form of point systems, rewards, penalty systems, and competitive structures and more of an emphasis on teacher direction and student compliance; CDP program classrooms used more cooperative and social-understanding activities and made greater provision for student autonomy.

The EXS school was described by its teachers as being more active, involved, businesslike, and creative; as having more involved and supportive parents, a more supportive and accessible principal, a more traditional academic focus, a more pleasant atmosphere; as being more creative and innovative; and as having better relations between teachers and students. It is possible, despite the strong and pervasive district philosophy, that these differences may reflect idiosyncratic characteristics of this particular school rather than the effects of the educational program it shares with other schools in that district. Because the other two conditions in this study are represented by three schools each (although both conditions are in the same district), the case for their generalizability may be stronger. Any educational program must, of course, take place in a particular school setting, and so, to the degree that it is possible to generalize from the present findings, it would be necessary to consider them to stem from the operation of these particular school programs in the kinds of settings represented by these school climate descriptors.
Moreover, the two programs that we contrast here are actually similar in many respects. In both, teachers emphasize some form of positive student behavior and students are involved in a certain amount of within-group cooperative activity. This cooperative activity is in the service of competition between groups in the EXS school, but not in the CDP program schools. Classrooms in the latter schools conduct more formal cooperative learning activities. Thus it would be misleading to describe one program as purely competitive and the other as purely cooperative. Perhaps the clearest difference between the programs is in the use of a systematic, comprehensive system of standards for performance, rewards, and controls in the EXS school, compared with a minimization of external control and an emphasis on intrinsic incentives in the CDP schools.

The positive, sustained effect on students' self-esteem in the EXS school is an important consideration for further research. This finding was stable and consistent but relatively weak and may reflect the differences in the general school climates. The combination of positive interpersonal relationships between teachers, parents, principal, and students; high levels of structured activity; and a clearly defined classroom and school structure that appears to be more characteristic of the EXS school seems to correspond to findings of socialization research on parenting (summarized by Maccoby, 1980, pp. 381-382). This parenting research indicated that children of parents who consistently enforced their rules and demands, in spite of noncompliance or resistance, were best able to control their aggressive impulses, were high in selfesteem at age 10 or 11 , and were able to approach new situations with confidence, to take initiative and persist in tasks once begun, and to be generally positive in mood.

The EXS students' high self-esteem may also be enhanced by the more frequent and explicit feedback and recognition they receive for their performance in a broader 
range of school activities. This suggestion is consistent with research documenting the relationship between high parental expectations and children's sense of competence and self-reliance (Maccoby, 1980, pp. 382383 ), as well as the cluster of traits described by Baumrind (1973) as promoting children's instrumental competence, a combination of parental control, clarity of communication, maturity demands, and nurturance (i.e., concern for the children's well-being and pleasure in their accomplishments).

However, these findings do not warrant firm conclusions about the effects of competitive versus cooperative settings, or extrinsic versus intrinsic incentive systems on students' self-esteem. As indicated earlier, the EXS program included both cooperation (within groups) and competition (between groups), whereas the CDP program students, although more strictly focused on academic cooperation within the school, were undoubtedly also involved in competitive group activities outside of school (e.g., soccer, baseball, etc.). Definitive answers concerning the effects of cooperative learning and external control systems on self-esteem must await further research.

Students' extrinsic prosocial motivation, another major outcome variable of our study, seems more clearly attributable to characteristics of the programs studied. Students' extrinsic prosocial motivation was significantly higher in the EXS school, where a high proportion of their activity was guided or controlled by externally imposed rewards and penalties, and was lower in the two sets of CDP schools, which used such techniques less frequently.

These findings are consistent with the notion that the use of extrinsic incentive systems in childhood creates a dependence on the receipt of rewards or the avoidance of punishments to motivate and maintain behaviors (Lepper \& Greene, 1978). It should be pointed out, however, that the items that constitute these measures are primarily concerned with school settings. The degree to which the findings would gen- eralize to nonschool settings, or to observed behavior, as opposed to responses to hypothetical interview and questionnaire situations, is unknown at this point.

At the least, the findings indicate that elementary school students in an externally controlled setting are more likely to see themselves and others as being motivated by extrinsic factors. Whether such external controls may later become internalized and ultimately contribute to self-direction and self-regulation, as some have suggested (e.g., Bloom, 1985; Gage \& Berlinger, 1988), but others have disputed (e.g., Lepper, 1983), is a question deserving further study.

There was, finally, some evidence that students' interpersonal behavior was more helpful and supportive in the CDP program classrooms than in the other two settings (indicated in the third-grade classroom observations and the fifth-grade student questionnaire). Even though most of the indicators did not show statistically significant differences, the observation data produced the largest, though inflated, effect sizes of any of the student outcome measures and thus merit attention. These effects can probably be attributed to differences in the ways the classrooms were conceptualized and operated.

In summary, although there were major differences between the programs studied, both seem to have had positive effects on students, with effects in the EXS school perhaps magnified by the quite positive school climate. There were also numerous areas in which neither program was significantly or consistently differentiated from the comparison group of schools, most notably with respect to small-group behavior away from the classroom. Further efforts to examine the degree to which effects of these programs generalize to settings other than the classroom are called for. In addition, it would be valuable to explore the programs in larger numbers of classrooms, so that their effects can be more clearly disentangled from the characteristics of the particular schools and classrooms in which 
they are implemented, and to examine the effects of particular aspects of the programs (e.g., extrinsic vs. intrinsic incentives, different combinations of cooperation and competition).

Despite the limitations of the present study, the findings do underscore the general assumption that school and classroom settings and activities have important effects on children's social development. Such effects, as produced or influenced by varied educational settings-including but not limited to the types represented in the present study-warrant extensive further investigation.

Note

The research described in this article was funded by grants from California State University, Fresno, and the William and Flora Hewlett Foundation, Menlo Park, CA.

\section{References}

Barnett, M. A., Matthews, K. A,, \& Howard, J. A. (1979). Relationship between competitiveness and empathy in 6- and 7-year-olds. Developmental Psychology, 15, 221-222.

Battisrich, V., Watson, M., Solomon, D., Schaps, E., \& Solomon, J. (in press). The Child Development Project: A comprehensive program for the development of prosocial character. In W. M. Kurtines \& J. L. Gewirtz (Eds.), Moral behavior and development: Vol. 1. Advances in theory, research and application. New York: Erlbaum.

Baumrind, D. (1973). The development of instrumental competence through socialization. In A. D. Pick (Ed.), Minnesota symposium on child psychology (Vol. 7). Minneapolis: University of Minnesota Press.

Bloom, B. S. (Ed.). (1985). Developing talent in young people. New York: Ballantine.

Cohen, E. G. (1987). Designing group work: Strategies for the heterogeneous classroom. New York: Teachers College Press.

Deci, E. L., Schwartz, A. J., Sheinman, L., \& Ryan, R. M. (1981). An instrument to assess adults' orientations toward control versus autonomy with children: Reflections on intrinsic motivation and perceived competence. Journal of Educational Psychology, 73, 642-650.

Deer, J., Solomon, J., Watson, M., \& Solomon, D. (1988). Assessment of children's motives, attitudes, values and perceptions. Moral Education Forum, 13, 18-34, 37.

Gage, N. L., \& Berliner, D. C. (1988). Educational psychology. Boston: Houghton Mifflin.

Johnson, D. W., \& Johnson, R. T. (1974). Instructional goal structure: Cooperative, competitive, or individualistic. Review of Educational Research, 44, 213-240.

Johnson, D. W., Johnson, R. T., \& Anderson, D. (1983). Social interdependence and classroom climate. Journal of Psychology, 114,135142.

Johnson, D. W., Johnson, R. T., \& Maruyama, G. (1981). Interdependence and interpersonal attraction among heterogeneous and homogeneous individuals: A theoretical formulation and meta-analysis of the research. Review of Educational Research, 53, 5-54.

Lepper, M. R. (1983). Extrinsic reward and intrinsic motivation: Implications for the classroom. In J. M. Levine \& M. C. Wang (Eds.), Teacher and student perceptions (pp. 281317). Hillsdale, NJ: Erlbaum.

Lepper, M. R., \& Greene, D. (1978). Overjustification research and beyond: Towards a means-end analysis of intrinsic and extrinsic motivation. In M. R. Lepper \& D. Greene (Eds.), The hidden costs of reward (pp. 109148). Hillsdale, NJ: Erlbaum.

Maccoby, E. (1980). Social development: Psychological growth and the parent-child relationship. New York: Harcourt Brace Jovanovich.

Michaels, J. W. (1977). Classroom reward structures and academic performance. Review of Educational Research, 47, 87-98.

Morgan, M. (1984). Reward-induced decrements and increments in intrinsic motivation. Review of Educational Research, 54, 5-30.

Ryan, R. M., Connell, J. P., \& Deci, E. L. (1985). A motivational analysis of self-determination and self-regulation in education. In $\mathrm{C}$. Ames \& R. Ames (Eds.), Research on motivation in education. Vol. 2. The classroom milieu (pp. 13-51). New York: Academic Press.

Sharan, S. (1980). Cooperative learning in small groups: Recent methods and effects on achievement, attitudes, and ethnic relations. Review of Educational Research, 50, 241-271.

Sharan, S., \& Hertz-Lazarowitz, R. (1980). A group-investigation method of cooperative learning in the classroom. In S. Sharan, P. Hare, C. Webb, \& R. Hertz-Lazarowitz 
(Eds.), Cooperation in education (pp. 14-46). Provo, UT: Brigham Young University Press.

Slavin, R. E. (1980). Using student team learning. Baltimore: Johns Hopkins University, Center for Social Organization of Schools.

Slavin, R. E. (1983). Cooperative learning. New York: Longman.

Slavin, R. E. (1984). Students motivating students to excel: Cooperative incentives, cooperative tasks, and student achievement. Elementary School Journal, 85, 53-63.

Slavin, R. E. (1987). Cooperative learning and the cooperative school. Educational Leadership, 45, 7-13.

Solomon, D., Watson, M. S., Delucchi, K. L., Schaps, E., \& Battistich, V. (1988). Enhancing children's prosocial behavior in the classroom. American Educational Research Journal, 25, 527-54.

Solomon, D., Watson, M. S., Schaps, E., Battistich, V., \& Solomon, J. (1990). Cooperative learning as part of a comprehensive program designed to promote prosocial development. In S. Sharan (Ed.), Cooperative learning: Theory and research (pp. 231-260). New York: Praeger.

Stone, C, Solomon, J., Tauber, M., \& Watson, M. (1989). Procedures for assessing children's social behavior: Four-person tasks. Moral Education Forum, 14, 12-21.

Tauber, M., Rosenberg, M., Battistich, V., \& Stone, C. (1989). Procedures for assessing children's social behavior: Dyadic tasks. Moral Education Forum, 14, 1-11.

Watson, M., Schaps, E., Battistich, V., Solomon, D., \& Solomon, J. (1989). The Child Development Project: A values education program that combines traditional and developmental approaches. In L. Nucci (Ed.), Moral development and character education: A dialogue (pp. 51-92). Berkeley, CA: McCutchan. 